\title{
The Association Between Glycemic Variability and Myocardial Infarction: A Review and Meta- Analysis of Prospective Studies and Randomized Trials
}

Zinab Alatawi ${ }^{1}$, Hyder Mirghani ${ }^{2}$

1. Family Medicine, University of Tabuk, College of Medicine, Tabuk, SAU 2. Internal Medicine, University of Tabuk, Tabuk, SAU

Corresponding author: Zinab Alatawi, zalatawi@ut.edu.sa

\begin{abstract}
Diabetes mellitus is a major risk factor for vascular complications and mortality, glycemic variability (GV) has emerged as a measure of time and magnitude of plasma glucose, its association with cardiovascular complications is controversial. The current study aimed to assess the association of GV with myocardial infarction. An electronic literature search was conducted in PubMed, Medline, and Google Scholar databases for relevant articles. Articles in the English language during the period from 2010 to April 2020 were eligible. The keywords fasting blood glucose variability (FBGV), glucose variability, myocardial infarction, and acute coronary syndrome, were used with the protean OR and AND. Out of the 185 articles retrieved, only seven full texts fulfilled the inclusion and exclusion criteria. The author's name, year of publication, the study type, number of patients, and the results were extracted. There were seven full texts, one from Brazil, one from Australia, two from the USA, and three from Asia. Two were randomized controlled trials and five were prospective cohorts (included 109,058 participants). A significant negative association was found between GV and myocardial infarction, odd ratio (OD) $1.93,95 \% \mathrm{CI}=1.08-3.44, \mathrm{P}$-value $=0.03, \mathrm{I}^{2}$ for heterogeneity $=87 \%, \mathrm{P}$-value $=0.0001$. However, it is difficult to reach a conclusion due to the small number of the included studies and the high heterogeneity observed. Further well-controlled trials using the same methods are needed to resolve the issue.
\end{abstract}

Review began 09/20/2020 Review ended 11/18/2020 Published 11/18/2020

๑) Copyright 2020 Alatawi et al. This is an open access article distributed under the terms of the Creative Commons Attribution License CC-BY 4.0., which permits unrestricted use, distribution, and reproduction in any medium, provided the original author and source are credited.
Categories: Endocrinology/Diabetes/Metabolism, Family/General Practice

Keywords: glucose variability, myocardial infarction, hba1c variability

\section{Introduction And Background}

Glycemic variability (GV) is a major issue when evaluating the degree of glycemic control. It also correlates with hypoglycemia, and GV increases from prediabetes to advanced type 2 diabetes (T2D) and is still high in type 1 diabetes mellitus. Many metrics exist to measure GV (\%Coefficient of Variation and the standard deviation are the most popular) [1].

Glucose fluctuation is associated with inflammation, oxidative stress, and endothelial dysfunction, factors that are to blame in the pathogenesis of vascular damage [2]. Increased variability of fasting blood glucose (FBG) is independently associated with the development of T2D [3,4]. There is an increasing awareness regarding the possible detrimental effects of GV on the coronary arteries and the role of targeting it as an interventional strategy for prevention [5]. Retrospective studies [4,6,7] showed that glycemic variability is linked to myocardial infarction, stroke, and all-cause mortality among prediabetes and normoglycemic individuals. The literature on the association of fasting blood glucose variability (FBGV) with coronary artery disease scares. The current review aimed to assess the relationship between FBGV and myocardial infarction.

\section{Review}

\section{Methodology}

Eligibility Criteria According to PICOS (Patient/Population, Intervention, Comparison and Outcomes)

Type of studies included: All randomized controlled studies and prospective on humans were included, retrospective cohorts, case reports, case series, animal, and experimental studies were excluded. Participants: All adults in whom myocardial infarction and GV were measured. Outcomes measures: Studies were included if they assessed glucose variability and myocardial infarction.

Information Sources and Search Methods

A systematic manual search was conducted in PubMed, Medline, and the first 100 articles in Google Scholar 


\section{Cureus}

in the last 10 years from 2010 to April 2020; the following keywords were used, fasting plasma glucose variability, myocardial infarction, hemoglobin A1c (HbA1c) variability, and glycemia variability with protean OR, and AND in different combinations.

Study Selection and Data Extraction

Two authors screened the titles and abstracts independently for relevant articles and irrelevant articles were removed, and the discrepancy between the two authors was solved by consensus. The author's name, year of publication, type of study, the number of patients included, and the findings of the studies were recorded.

Out of the 185 articles screened, only seven full texts were eligible after applying the inclusion and exclusion criteria (Figure 1).

185records identified through the database search

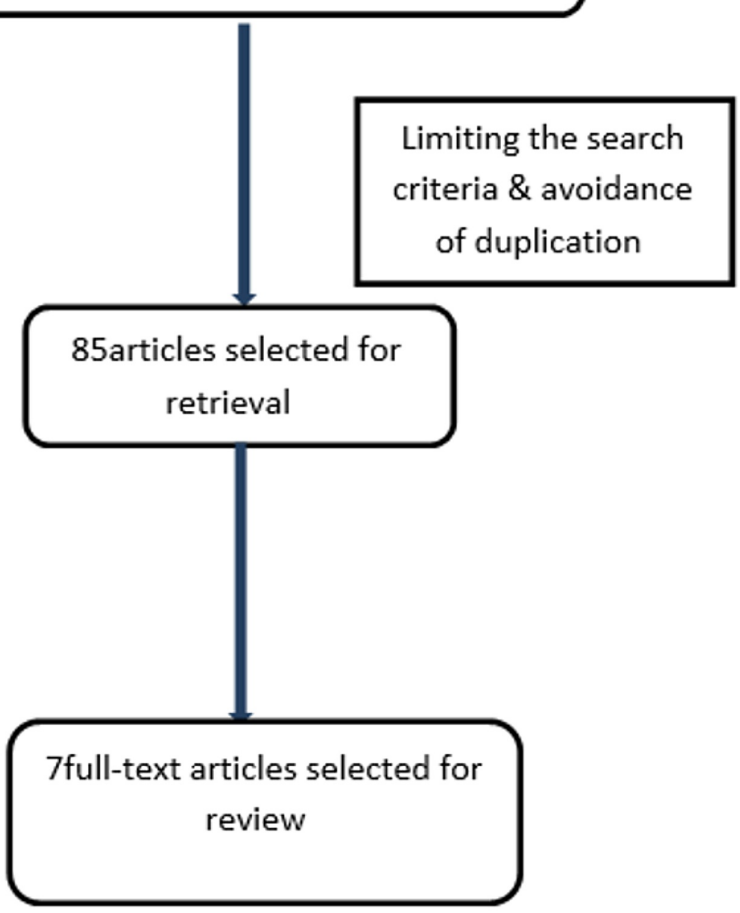

FIGURE 1: The different phases of the literature search

Statistical Analysis

RevMan 5.4 software (Cochrane, London, UK) was used for the meta-analysis. For glycemic variability (binary) risk ratios (RRs) with 95\% confidence intervals (CIs) were combined across relevant studies, the random effects module was applied due to substantial heterogeneity (A P value $\leqslant 0.10$ for Cochran's $Q$ test or an I2 $\geqslant 50 \%$ was suggestive). A two-tailed P $<005$ was considered statistically significant for all analyses except heterogeneity tests.

\section{Results}

There were seven studies, one from Brazil, one from Australia, two from the USA, and the rest from Asia. Two were randomized controlled trials and five prospective cohorts (Table 1). In the present review, of the seven studies included in the meta-analysis four showed a negative association between myocardial infarction and GV [8-11], while three showed a neutral effect [12-14], the studies included 109,058 participants. A negative significant association was found between glycemic variability and myocardial infarction, odd ratio, 1.93 , 95\% CI=1.08-3.44, P-value=0.03, I2 for heterogeneity $=87 \%, \mathrm{P}$-value $=0.0001$ (Figures 2, 3) 


\section{Cureus}

\begin{tabular}{|c|c|c|c|c|c|}
\hline Author & Year & Country & $\begin{array}{l}\text { Type of } \\
\text { study }\end{array}$ & No of patients & result \\
\hline $\begin{array}{l}\text { Hirakawa et al. } \\
\text { [13] }\end{array}$ & 2014 & Australia & RCT & $\begin{array}{l}4,399 \text { patients } \\
\text { followed for } 24 \\
\text { months }\end{array}$ & $\begin{array}{l}\text { Glucose variability was associated with vascular damage } \\
\text { and death }\end{array}$ \\
\hline Jin et al. [8] & 2017 & China & Prospective & $\begin{array}{l}68,297 \text { followed for } \\
4 \text { years }\end{array}$ & An increasing rate of FBG predicted future risk of Ml. \\
\hline Wang et al. [9] & 2017 & China & $\begin{array}{l}\text { Longitudinal } \\
\text { cohort }\end{array}$ & $\begin{array}{l}53607 \text { followed for } \\
4.93 \text { years }\end{array}$ & $\begin{array}{l}\text { PG variability linked to mortality and cardiovascular } \\
\text { disease irrespective of FPG }\end{array}$ \\
\hline Yoon et al. [14] & 2017 & Korea & $\begin{array}{l}\text { Prospective } \\
\text { cohort }\end{array}$ & $\begin{array}{l}674 \text { TIA and stroke } \\
\text { (3 months) }\end{array}$ & $\begin{array}{l}\text { The initial glycemic variability might increase } \mathrm{CV} \text { events in } \\
\text { acute ischemic stroke patients with diabetes }\end{array}$ \\
\hline $\begin{array}{l}\text { Cardoso et al. } \\
{[10]}\end{array}$ & 2018 & Brazil & $\begin{array}{l}\text { A } \\
\text { prospective } \\
\text { cohort }\end{array}$ & $\begin{array}{l}654 \text { patients } \\
\text { followed for } 9.3 \\
\text { years }\end{array}$ & $\begin{array}{l}\text { Glucose variability predicted both micro and } \\
\text { macrovascular complications }\end{array}$ \\
\hline $\begin{array}{l}\text { Echouffo- } \\
\text { Tcheugui et al. } \\
\text { [12] }\end{array}$ & 2019 & USA & $\begin{array}{l}\text { Prospective } \\
\text { cohort }\end{array}$ & $\begin{array}{l}4982 \text { followed for } \\
\text { five years }\end{array}$ & $\begin{array}{l}\text { visit-to-visit variability in FPG was associated with } \\
\text { increased mortality }\end{array}$ \\
\hline Zhou et al. [11] & 2019 & USA & RCT & $\begin{array}{l}1791 \text { followed for } 84 \\
\text { months }\end{array}$ & $\begin{array}{l}\text { Fasting glucose variability was linked to mortality after } \\
\text { controlling for hypoglycemia and lifestyle }\end{array}$ \\
\hline
\end{tabular}

TABLE 1: Fasting blood glucose variability association with cardiovascular risks and diabetes mellitus development

RCT: randomized controlled trial, FPG: fasting plasma glucose test, DM: diabetes mellitus, FBG: fasting blood glucose, MI: myocardial infarction, T2D: type 2 diabetes, TIA: transient ischemic attack, CV: cardiovascular

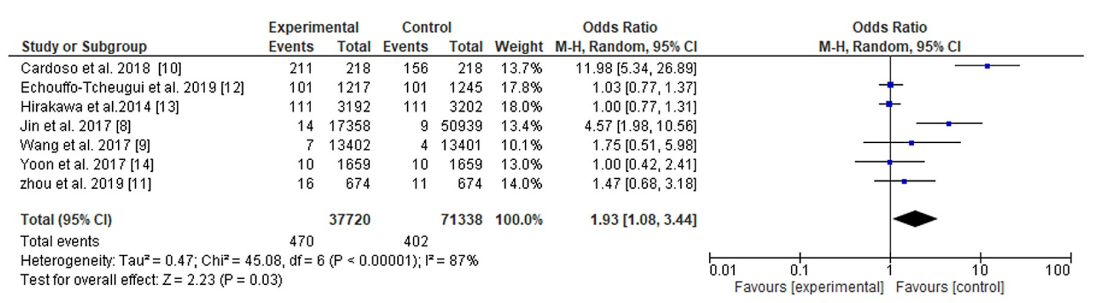

FIGURE 2: Glycemic variability and myocardial infarction risk 


\section{Cureus}

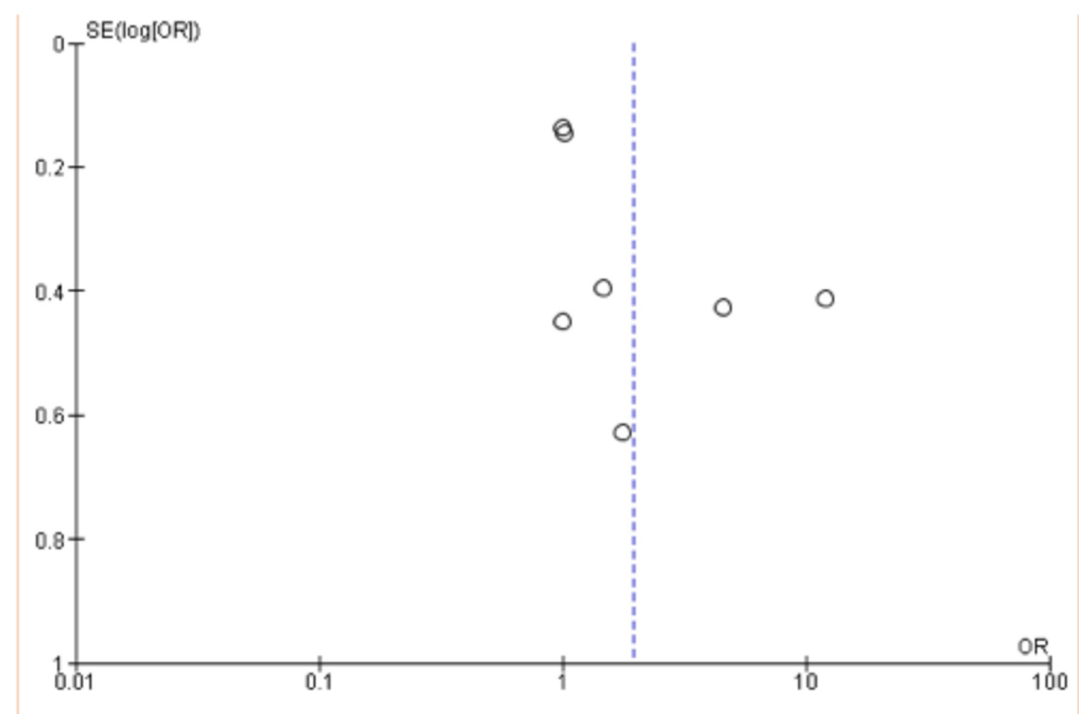

FIGURE 3: Glycemic variability and myocardial infarction risk

SE: standard error, OR: odds ratio

\section{Discussion}

In the present review, of the seven studies included in the meta-analysis four showed a negative association between myocardial infarction and GV [8-11], while three showed a neutral effect [12-14], the studies included 109,058 participants. A significant negative association was found between GV and myocardial infarction: odd ratio, $1.93,95 \% \mathrm{CI}=1.08-3.44$, P-value $=0.03$, I2 for heterogeneity $=87 \%, \mathrm{P}$-value $=0.0001$. Smith-Palmer and colleagues [15] conducted a systematic review among patients with diabetes mellitus and found an association between glucose variability and myocardial infarction in type 1 diabetes, while the findings were inconsistent in type 2 diabetes, a review published in China [16] stated that GV may be a marker of increased progression of coronary disease and plaque vulnerability in contradiction to our finding; a plausible explanation might be the small number and different methods of the studies included, glucose variability is thought to induce more oxidative stress predisposing to vascular damage $[17,18]$. Although there is no gold standard measure for glucose variability, standard deviation estimated from selfmonitoring blood glucose and the mean amplitude of glycemic excursions calculated from the continuous glucose monitoring are in common use.

The current study is unique in that it is the first to conduct a meta-analysis and include randomized and prospective study, the limitations were the small number of the included studies and the heterogeneity reported that might be due to the different methods of assessing glucose variability. Nevertheless, the current finding brought an issue that needs consideration and calls for further studies in this important area of research that was not well-covered in the current literature. Further well-controlled studies and including continuous glucose monitoring, strict dietary approach, and using the standard deviation to assess both intraday and inter-day variability are needed.

\section{Conclusions}

Glucose variability is negatively associated with the development of myocardial infarction. However, it is difficult to reach a conclusion due to the small number of the included studies and the high heterogeneity observed.

\section{Additional Information \\ Disclosures}

Conflicts of interest: In compliance with the ICMJE uniform disclosure form, all authors declare the following: Payment/services info: All authors have declared that no financial support was received from any organization for the submitted work. Financial relationships: All authors have declared that they have no financial relationships at present or within the previous three years with any organizations that might have an interest in the submitted work. Other relationships: All authors have declared that there are no other relationships or activities that could appear to have influenced the submitted work. 


\section{References}

1. Rodbard D: Glucose variability: a review of clinical applications and research developments . Diabetes Technol Ther. 2018, 20:25-215. 10.1089/dia.2018.0092

2. Škrha J, Šoupal J, Škrha J Jr, Prázný M: Glucose variability, HbA1c and microvascular complications . Rev Endocr Metab Disord. 2016, 17:103-10. 10.1007/s11154-016-9347-2

3. Mozaffary A, Asgari S, Tohidi M, Kazempour-Ardebili S, Azizi F, Hadaegh F: Change in fasting plasma glucose and incident type 2 diabetes mellitus: results from a prospective cohort study. BMJ Open. 2016, 23:010889. 10.1136/bmjopen-2015-010889

4. Kim JA, Lee JS, Chung HS, et al.: Impact of visit-to-visit fasting plasma glucose variability on the development of type 2 diabetes: a nationwide population-based cohort study. Diabetes Care. 2018, 41:26102616. 10.2337/dc18-0802

5. Xia J, Yin C: Glucose variability and coronary artery disease. Heart Lung Circ. 2019, 28:553-559. 10.1016/j.hlc.2018.10.019

6. Lee G, Kim SM, Choi S, et al.: The effect of change in fasting glucose on the risk of myocardial infarction, stroke, and all-cause mortality: a nationwide cohort study. Cardiovasc Diabetol. 2018, 7:51. 10.1186/s12933018-0694-Z

7. Yu JH, Han K, Park S, et al.: Effects of long-term glycemic variability on incident cardiovascular disease and mortality in subjects without diabetes: a nationwide population-based study. Medicine (Balt). 2019, 98:16317. 10.1097/MD.0000000000016317

8. Jin C, Chen S, Vaidya, et al.: Longitudinal change in fasting blood glucose and myocardial infarction risk in a population without diabetes. Diabetes Care. 2017, 40:1565-1572. 10.2337/dc17-0610

9. Wang A, Liu X, Xu J, et al.: Visit-to-visit variability of fasting plasma glucose and the risk of cardiovascular disease and all-cause mortality in the general population. J Am Heart Assoc. 2017, 29:006757. 10.1161/JAHA.117.006757

10. Cardoso CR, Leite NC, Moram CB, Salles GF: Long-term visit-to-visit glycemic variability as predictor of micro- and macrovascular complications in patients with type 2 diabetes: the Rio de Janeiro Type 2 Diabetes Cohort Study. Cardiovasc Diabetol. 2018, 24:33. 10.1186/s12933-018-0677-0

11. Zhou JJ, Koska J, Bahn G, Reaven P: Glycaemic variation is a predictor of all-cause mortality in the Veteran Affairs Diabetes Trial. Diab Vasc Dis Res. 2019, 16:178-185. 10.1177/1479164119827598

12. Echouffo-Tcheugui JB, Zhao S, Brock G, Matsouaka RA, Kline D, Joseph JJ: Visit-to-visit glycemic variability and risks of cardiovascular events and all-cause mortality: the ALLHAT study. Diabetes Care. 2019, 42:486493. $10.2337 /$ dc18-1430

13. Hirakawa Y, Arima H, Zoungas S, et al.: Impact of visit-to-visit glycemic variability on the risks of macrovascular and microvascular events and all-cause mortality in type 2 diabetes: the ADVANCE trial. Diabetes Care. 2014, 37:2359-65. 10.2337/dc14-0199

14. Yoon JE, Sunwoo JS, Kim JS, Roh H, Ahn MY, Woo HY, Lee KB: Poststroke glycemic variability increased recurrent cardiovascular events in diabetic patients. J Diabet Comp. 2017, 31:390-394. 10.1016/j.jdiacomp.2016.11.014

15. Smith-Palmer J, Brändle M, Trevisan R, Orsini Federici M, Liabat S, Valentine W: Assessment of the association between glycemic variability and diabetes-related complications in type 1 and type 2 diabetes. Diabetes Res Clin Pract. 2014, 105:273-84. 10.1016/j.diabres.2014.06.007

16. Jung HS: Clinical implications of glucose variability: chronic complications of diabetes . Endocrinol Metab. 2015, 30:167-74. 10.3803/EnM.2015.30.2.167

17. Xia J, Yin C: Glucose variability and coronary artery disease. Heart Lung Circ. 2019, 28:553-559. 10.1016/j.hlc.2018.10.019

18. Kim MK, Han K, Park YM, Kwon HS, Kang G, Yoon KH, Lee SH: Associations of variability in blood pressure, glucose and cholesterol concentrations, and body mass index with mortality and cardiovascular outcomes in the general population. Circulation. 2018, 138:2627-2637. 10.1161/CIRCULATIONAHA.118.034978 